\title{
Evaluation of 1.7 kV SiC MOSFETs for a Regenerative Cascaded H-Bridge Multilevel Converter Cell
}

N. Hildebrandt, M. Petkovic, and D. Dujic

This material is posted here with permission of the IEEE. Such permission of the IEEE does not in any way imply IEEE endorsement of any of EPFL's products or services. Internal or personal use of this material is permitted. However, permission to reprint / republish this material for advertising or promotional purposes or for creating new collective works for resale or redistribution must be obtained from the IEEE by writing to pubs-permissions@ieee. org. By choosing to view this document, you agree to all provisions of the copyright laws protecting it. 


\title{
Evaluation of $1.7 \mathrm{kV} \mathrm{SiC} \mathrm{MOSFETs} \mathrm{for} \mathrm{a}$ Regenerative Cascaded H-Bridge Multilevel Converter Cell
}

\author{
Nicolai Hildebrandt, Marko Petković and Dražen Dujić \\ Power Electronics Laboratory - PEL \\ École Polytechnique Fédérale de Lausanne - EPFL \\ Station 11, CH-1015 Lausanne, Switzerland \\ nicolai.hildebrandt@epfl.ch,marko.petkovic@epfl.ch,drazen.dujic@epfl.ch
}

\begin{abstract}
High fidelity AC grid emulators allow early testing and qualification of various equipment under conditions close to those expected in reality. Realizing this at medium voltage high power level is associated with certain challenges, some of which are discussed in this paper. Medium voltage grid emulator based on the well-known four-quadrant Robicon topology is considered as platform for realization of the $\mathrm{AC}$ grid emulator. To achieve high resolution AC waveform with sufficiently high control bandwidth, $\mathrm{SiC}$ based cell design is compared with pure $\mathrm{Si}$ and Hybrid ( $\mathrm{Si}+\mathrm{SiC})$ designs. Using $\mathrm{SiC}$ devices for the output H-bridge stage allows significantly higher switching frequencies, improving achievable control bandwidth and improving fidelity of emulator output voltage.
\end{abstract}

Index Terms-Grid Emulator, $\mathrm{CHB}, \mathrm{SiC}$

\section{INTRODUCTION}

Over the last two decades the use of distributed energy power generation increased rapidly. This led to growing concerns regarding grid stability and therefore tightened requirements found their way into standards and into codes issued by the grid operators. At the same time, advancements in power semiconductor technology and digital signal processing enabled researchers to build novel high-power electronic systems, like solid-state transformers, which bring additional capabilities to directly improve the medium-voltage grid stability and power quality.

Testing of grid-connected inverters from early stages of research and development to final qualification for compliance with standards requires test benches that can emulate normal and abnormal grid conditions. These are typically deviations in voltage amplitude, symmetry, frequency, phase angles, content of harmonics and sudden faults of the grid. The complexity of such a test bench can range from shunt inductors and tapped autotransformers to emulate voltage sags over series injection of voltage harmonics and programmable voltage sources [1] to power-hardware in-the-loop (PHiL) systems [2]. In PHiL systems the programmable voltage source is controlled by a real-time grid model simulation which reacts to the behavior of the equipment under test (EUT). In general, power electronics based solutions are most flexible regarding test scenarios and waveforms.

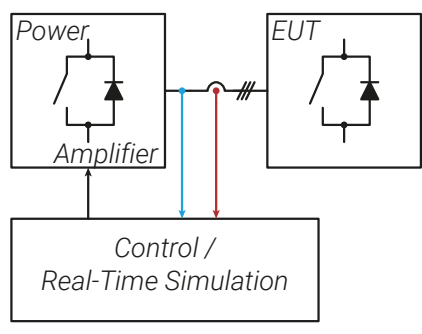

Fig. 1: Grid Emulator Setup

Depending on the testing purpose and depth, a programmable voltage source or a PHiL system can be used as a grid emulator. Both have in common a power amplifier (PA) unit which generates the emulated grid voltage and sinks or sources the currents delivered or consumed by the EUT as illustrated in Fig. 1.

While at low-voltage level linear voltage sources can be used as PA to create high precision, high dynamics and low noise waveforms, their losses are not permissible for test benches at high-power medium-voltage level. Switch-mode power converters, however, introduce harmonics around their switching frequency which can influence the EUT. The typical second order output filters used to mitigate this harmonic distortion for their part can limit the output dynamics of the PA if their cut-off frequency is low. Moreover, in order to be able to impose the desired grid voltage on the PA to EUT interface, the grid emulator needs a higher bandwidth than the EUT. These requirements can be addressed by a sufficiently increased switching frequency, which is a challenging endeavor if the PA is rated for high power.

Main approaches to reach higher switching frequency and dynamics in this case are series voltage injection by a second inverter [3][4], interleaved parallel operation of inverters or phases [5][6] and multilevel inverters. The latter offer a higher apparent output switching frequency than their two- or threelevel counterparts with the same output voltage and power rating. A high number of levels can be achieved with modular cell based inverters. While the use of modular multilevel converter (MMC) has been demonstrated in [7], this work 
considers the use of the Cascaded H-Bridge (CHB) converter [8][9] with four-quadrant (4Q) cell design. Advantages offered by Silicon Carbide (SiC) devices are compared with more common Silicon ( $\mathrm{Si}$ ) based solutions.

\section{CHB BASED GRID EMULATOR}

The grid emulator shall generate a precisely controllable voltage from zero to full line voltage of $6 \mathrm{kV}$ ac with various types of grid voltage disturbances: symmetrical and unbalanced voltage sags, swells, harmonic disturbances, frequency and phase angle variations with up to 1 MVA output power at $50 \mathrm{~Hz}$ nominal fundamental frequency.

Emerging conversion structures such as solid state transformers or even established MMCs, push the required switching frequencies to higher values. Typical switching frequencies of state-of-the-art drives below 1 MVA stay below $5 \mathrm{kHz}$, thus having a 5 times higher bandwidth and switching frequency should provide sufficient flexibility for tests.

In case of voltage harmonics injection up to $25^{\text {th }}$ harmonic, which is the highest harmonic explicitly defined in EN 50160 [10], the calculation can be as following in closedloop control case: If an LC output filter is used, an order of magnitude frequency distance should be kept between the resonance frequency and the desired harmonic frequency to limit the effects of the phase-shift introduced by the filter. The switching frequency then should be at least 4 times higher than the resonance frequency, depending on the control method used, which is at least $50 \mathrm{~Hz} \cdot 25 \cdot 10 \cdot 4=50 \mathrm{kHz}$ or even $100 \mathrm{kHz}$ to damp the switching ripple to less than $1 \%$. As such a high switching frequency is hard to be reached with $\mathrm{Si}$ devices, $\mathrm{SiC}$ devices are naturally considered as a feasible approach, despite their higher cost.

Finally, the impact on the grid that supplies the grid emulator shall be kept low in terms of input current power factor and distortion both in stationary operation and during transients at the grid emulator output.

The CHB topology shown in Fig. 2 is well-established in medium-voltage applications. Most of the produced highpower CHB converters are non-regenerative, i.e. their cells have a diode front-end, and operate in drive applications with low demand on dynamics like fans or pumps. This makes the design and control of the cells simple and cost-effective.

The output terminals of $N$ low-voltage cells are connected in series to give a multilevel medium-voltage phase voltage which can directly be applied to a machine. Typically, phaseshifted carrier PWM (PSC-PWM) [11] with carrier frequency between 400 and $1000 \mathrm{~Hz}$ is used as it evenly distributes the switching and conduction losses among all the silicon IGBT (Si IGBT) switches of the inverter H-Bridge (HB) stages. This increases the apparent switching frequency seen at the output as $N \cdot f_{\text {sw,cell }}$.

In applications where regenerative breaking is economically sensible, the diode front-ends are replaced or extended by silicon IGBT based Active Front-Ends (AFEs) with switching frequencies from $1.25 \mathrm{kHz}$ [12] to $10 \mathrm{kHz}$ [13]. Transformer secondary windings are shifted by multiples of $60^{\circ} / N$ to

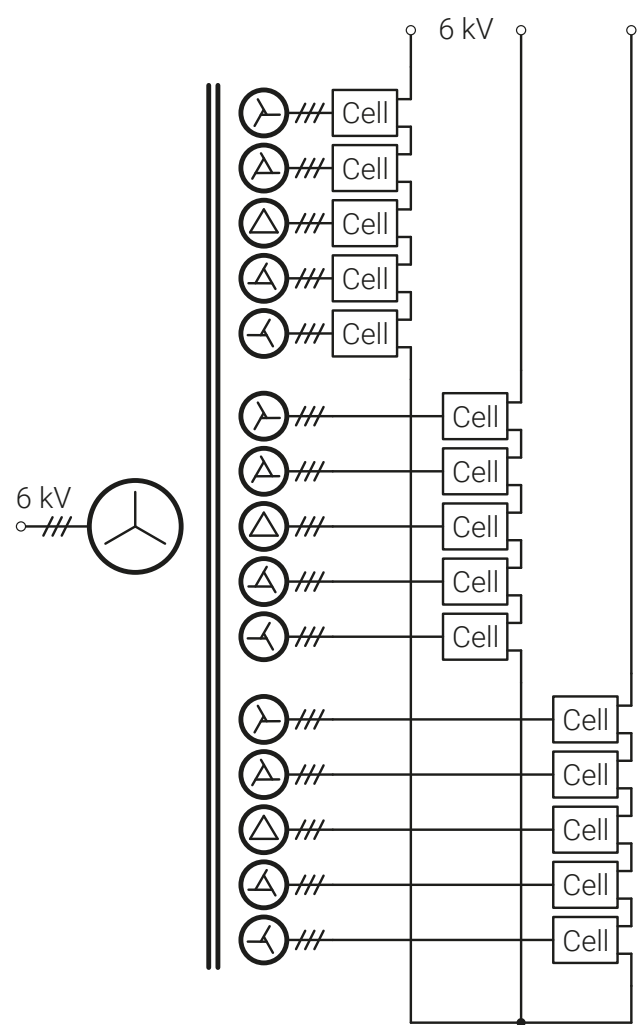

Fig. 2: Cascaded H-bridge topology

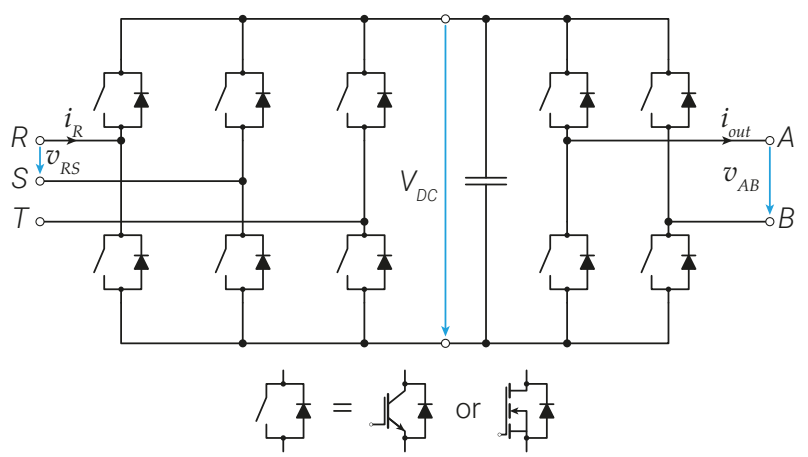

Fig. 3: Regenerative cell with an AFE stage (left) and inverter HB stage (right). Input filter is not shown.

cancel grid frequency current harmonics below harmonic order $6 \cdot N-1$. Therefore, the AFE current control bandwidth requirements is rather low. However, a higher switching frequency could reduce the filtering effort of the AFE switching harmonics and increase the bandwidth of the dc link voltage control for the emulated transients. As EUT can be both sink and source, the grid emulator has to be designed to be fully regenerative.

Having access to a multi-winding transformer with parameters provided in Table I, presence of only five secondary windings per phase implies relatively low multiplication factor ( $N=5$ ) for the apparent switching frequency, thus to increase the apparent switching frequency $\mathrm{SiC}$ devices are considered for $\mathrm{HB}$ stage. Yet, to provide fair and complete comparison, 
TABLE I: Multi-Winding Transformer Parameters

\begin{tabular}{cc}
\hline Parameter & Value \\
\hline \hline Apparent Power Rating & $1 \mathrm{MVA}$ \\
Primary Side Line Voltage & $6 \mathrm{kV}$ \\
Secondary Side Line Voltage & $710 \mathrm{~V}$ \\
Frequency & $50 \mathrm{~Hz}$ \\
Star Primary Windings & 1 \\
Extended Delta Secondary Windings & 15 \\
Phase Shifts of the Secondaries & $0^{\circ}, 12^{\circ}, 24^{\circ}, 36^{\circ}, 48^{\circ}$ \\
\hline
\end{tabular}

TABLE II: Regenerative Cell Parameters

\begin{tabular}{cc}
\hline Parameter & Value \\
\hline \hline Apparent Power Rating & $66.7 \mathrm{kVA}$ \\
AFE Nominal Current & $54 \mathrm{~A}$ \\
Inverter HB Nominal Current & $96 \mathrm{~A}$ \\
Maximum dc link voltage & $1200 \mathrm{~V}$ \\
Semiconductor blocking voltage & $1700 \mathrm{~V}$ \\
\hline AFE zero-sequence voltage injection & $\mathrm{min} / \mathrm{max}$ \\
Inverter HB zero-sequence voltage injection & none \\
AFE Modulation & triangle carrier PWM \\
Inverter HB Modulation & PSC-PWM \\
\hline
\end{tabular}

full $\mathrm{Si}$, full $\mathrm{SiC}$ as well as hybrid module and hybrid cell designs are evaluated. Cell ratings are summarized in Table II.

In our application, high dynamics has a higher weight than efficiency, thus a generous loss budget of $4 \%$ at nominal power is allocated for semiconductors alone.

\section{Power SEmiconductor Modules}

Fully qualified and commercially available power modules of the $1.7 \mathrm{kV}$ voltage class were evaluated, and as shown in Fig. 3 for simplicity reasons two-level switching cells are considered for both AFE and HB.

\section{A. Half-Bridge SiC Modules}

Currently, the choice of commercially available $1.7 \mathrm{kV} \mathrm{SiC}$ MOSFET halfbridge modules is very limited and the only considered modules are the Wolfspeed module [14] in an M6 screw terminals package and the Microsemi module [15] in a through-hole mounting package.

\section{B. Half-Bridge Si IGBT Modules}

In contrast to $\mathrm{SiC}$ MOSFET modules and $\mathrm{Si}$ IGBT / SiC SBD hybrid modules, there is a big choice of Si IGBT modules, so only several recent generation IGBTs like Infineon IGBT4 and similar of current classes up to $150 \mathrm{~A}$ were considered. Available half-bridges start at $75 \mathrm{~A}$ and six-packs at $100 \mathrm{~A}$. Various packages are used but $62 \mathrm{~mm}$ and EconoPACK ${ }^{\mathrm{TM}} 3$ and 4 mounting dimensions are most common for several manufacturers. One of the compared modules, a $150 \mathrm{~A}$ SEMIKRON module [16], was picked to represent this group.

\section{Half-Bridge Hybrid Modules}

Hybrid modules with Si IGBTs and SiC SBD could be a viable solution for reaching higher switching frequency or lower losses at moderate cost. The smallest module available
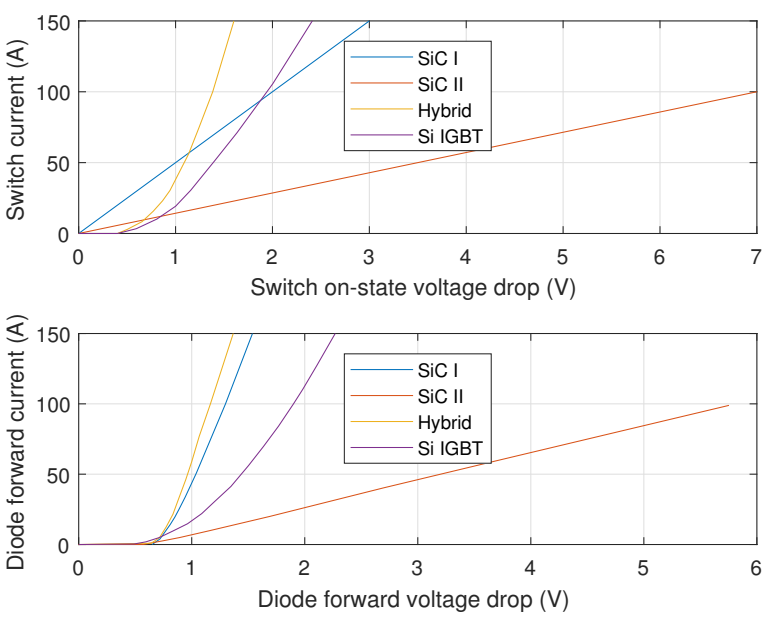

Fig. 4: Static characteristics. Junction temperature details are provided in Table III

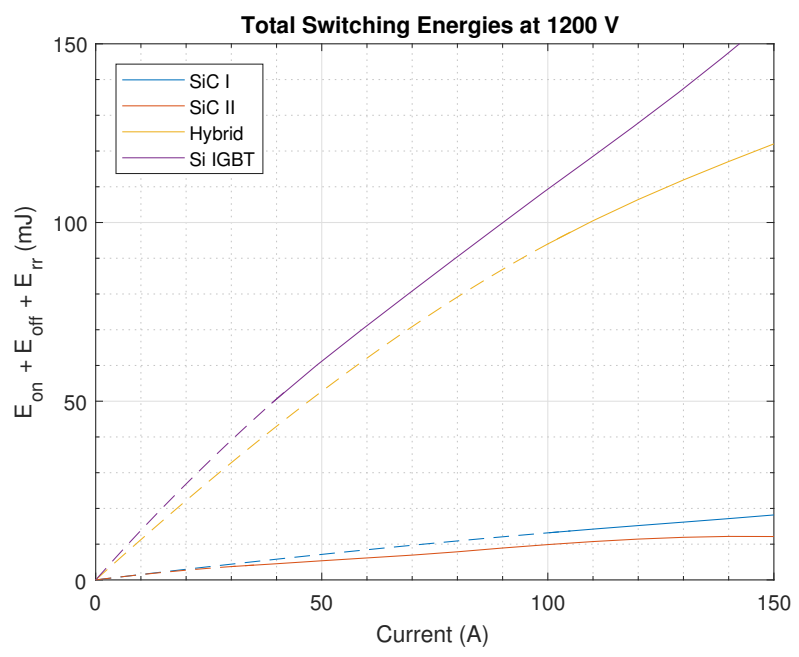

Fig. 5: Switching energies at 1200 V. Datasheet based values: solid lines, cubic interpolation: dashed lines. Junction temperatures and external gate resistor values are provided in Table III.

at the moment is rated at $400 \mathrm{~A}$ [17], so potential benefits of this technology can only be extrapolated for lower-rated modules.

The modules whose results are presented are listed in Table III. Short designators were assigned to simplify the descriptions throughout the paper.

Fig. 4 shows the hot conduction curves of the switches and co-packed diodes. One can already see that SiC II might be undersized for the full power rating in our application. Fig. 5 shows that the Hybrid module has about $15 \%$ lower switching losses than the Si IGBT despite more than two times higher $\mathrm{dc}$ current rating. The losses of both $\mathrm{SiC}$ devices are almost one order of magnitude below those of the Si IGBT and more similar than one would expect from their current ratings. 
TABLE III: Parameters of the Compared Power Semiconductor Modules

\begin{tabular}{llllllll}
\hline \multirow{2}{*}{ Halfbridge Module } & \multirow{2}{*}{ Short Designator } & \multirow{2}{*}{ Package } & \multicolumn{5}{c}{ Datasheet Parameters } \\
& & & $T_{\mathrm{j}, \mathrm{SW}}$ & $T_{\mathrm{j}, \mathrm{D}}$ & $R_{\mathrm{g}, \text { on }}$ & $R_{\mathrm{g}, \text { off }}$ & Ref. \\
\hline \hline CAS300M17BM2 & $\mathrm{SiC} \mathrm{I}$ & $62 \mathrm{~mm}$ & $150^{\circ} \mathrm{C}$ & $150^{\circ} \mathrm{C}$ & $2.5 \Omega$ & $2.5 \Omega$ & {$[14]$} \\
APTMC170AM30CT1AG & $\mathrm{SiC}$ II & $\mathrm{SP} 1$ & $150^{\circ} \mathrm{C}$ & $175^{\circ} \mathrm{C}$ & $10 \Omega$ & $10 \Omega$ & {$[15]$} \\
2MSI400VE-170-53 & Hybrid & $\mathrm{M} 277$ & $150^{\circ} \mathrm{C}$ & $150^{\circ} \mathrm{C}$ & $1 \Omega$ & $0.5 \Omega$ & {$[17]$} \\
SKM150GB17E4 & Si IGBT & $34 \mathrm{~mm}$ & $150^{\circ} \mathrm{C}$ & $150^{\circ} \mathrm{C}$ & $2 \Omega$ & $2 \Omega$ & {$[16]$} \\
\hline
\end{tabular}

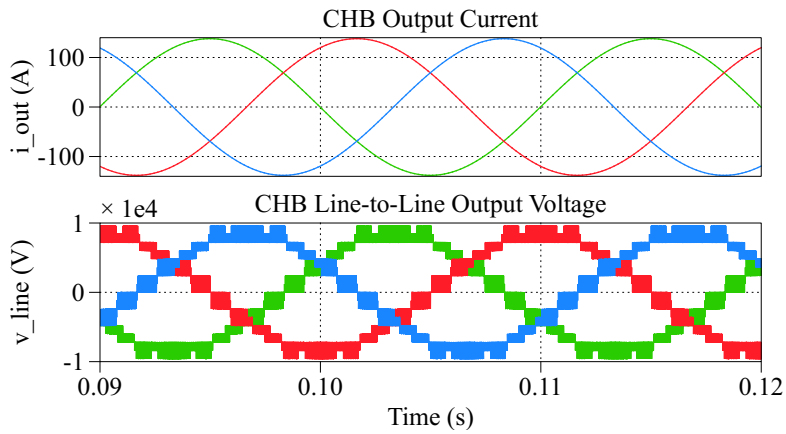

Fig. 6: Simulated CHB output waveforms for $1 \mathrm{MW}, P F=$ -1 and $f_{\mathrm{sw}, \text { cell }}=5 \mathrm{kHz}$

\section{Simulation Results}

\section{A. Semiconductor Loss Benchmark}

The input and output stages of the cell were modeled separately in Matlab / Simulink with PLECS blockset: the AFE of a single cell up to the constant voltage source as dc link, the cascaded HB output stages as 15 cells with constant voltage source at dc link.

Both stages were controlled with open loop PWM, the correct phase amplitude and phase angle were established by an accordingly parametrized interface impedance and ac voltage source. The modulation and zero-sequence voltage injection methods listed in Table II ensure a better dc link voltage utilization by the AFE and even distribution of switching and conduction losses among all switches. This way, additionally, only one transistor and diode per stage had to be observed. Fig. 6 shows waveforms of one of the benchmark operating points of the inverter HB cells.

The switching instants, voltage and current waveforms were recorded and used as identical dataset for the loss calculation of all semiconductors. The semiconductor loss models contain a linearization of the conduction curves and piece-wise cubic interpolations of multiple samples from the switching loss diagrams, both at high junction temperature; loss energies given at $900 \mathrm{~V}$ were linearly extrapolated to $1200 \mathrm{~V}$ dc link voltage which is our worst case. Besides equal benchmark conditions, this method is faster than simulation of each semiconductor separately if a high number of semiconductor models and/or high switching frequencies are involved.

In contrast to the calculation methods proposed in [18] the losses are simulated for the maximum operating junction temperature and do not assume partial reverse conduction through the intrinsic SiC MOSFET diode, whose current share depends on the junction temperatures and the actual conduction characteristics of the two diodes. Our results may therefore give some design margin in the real application.

\section{B. AFE - Power Losses}

Simulation results for losses per switch of the AFE for switching frequencies from 1.2 to $20 \mathrm{kHz}$ are shown in Fig. 7 . All modules showed similar results for both power flow directions: only conduction loss share of diode and switch are reversed for the opposite power factor. For power factor zero almost equal conduction losses in diode and switch were observed. In this paper, for both stages, power factor $P F=+1$ corresponds to power flow from dc to ac.

As expected Si IGBT modules with similar switching energies but different current ratings performed similarly as their switching losses dominate. Reverse recovery losses account for about $30 \%$ of the switching losses. The Hybrid module performed slightly better due to the negligible reverse recovery losses and reduced turn-on losses, despite the larger chip size. In contrast to the Si IGBT and the Hybrid switch, conduction losses dominate for SiC I module in general and for $\mathrm{SiC}$ II below $10 \mathrm{kHz}$ which is favorable when the AFE is operated at lower loading conditions.

The Hybrid module features lower losses than the Si IGBT module for switching frequencies above approximately $2 \mathrm{kHz}$, however, as the dissipated power increases rapidly to several hundreds of Watts per switch in both cases, the cooling effort, thermal cycling stress and switching transient duration may limit the maximum switching frequency below $10 \mathrm{kHz}$ which is sufficient in our case.

In contrast to that, a low cooling effort could be necessary for the SiC I device which additionally, as SiC device, has a superior thermal conductivity than the Si IGBT. Compared to $\mathrm{SiC}$ I, SiC II has higher losses in our AFE application and higher thermal resistances, however, it would still require a smaller heatsink at $20 \mathrm{kHz}$ than the Si IGBT module would do at $5 \mathrm{kHz}$ if thermal resistances of both were exactly equal.

\section{HB - Power Losses}

The difference between the modules is even more significant in the output stage due to higher currents: While the Si IGBT module can hardly be operated over $5 \mathrm{kHz}$ due to thermal limitations, Fig. 8a suggests that the $\mathrm{SiC}$ I module could be operated even significantly higher than $20 \mathrm{kHz}$ with a proper cooling.

Although most of the losses in the Hybrid module are still located in the Si transistor, see Fig. 8c, its chip area is much higher in the Hybrid module than in the Si IGBT module. Therefore the switching frequency could be increased 


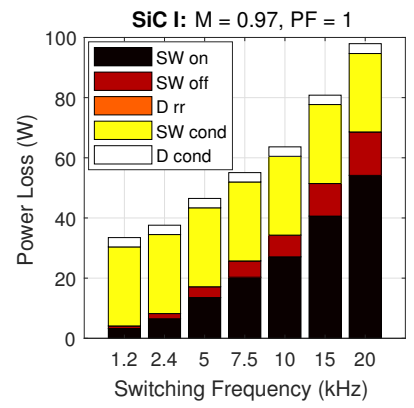

(a)

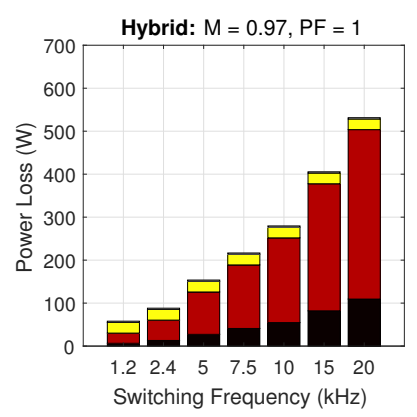

(c)

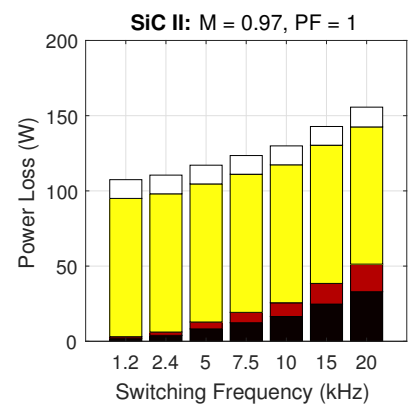

(b)

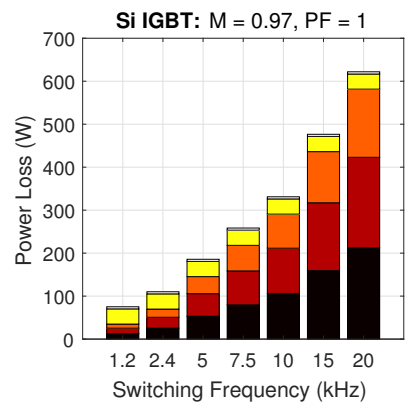

(d)

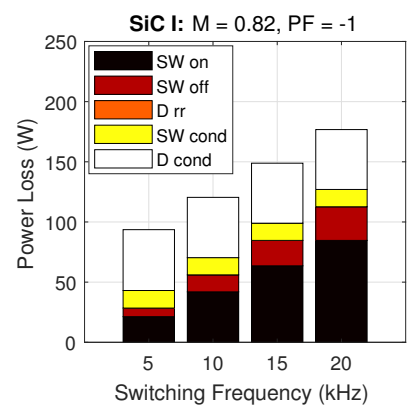

(a)

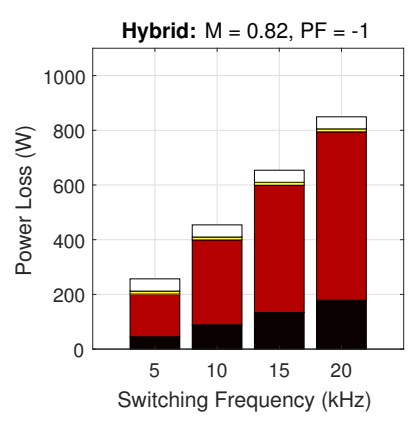

(c)

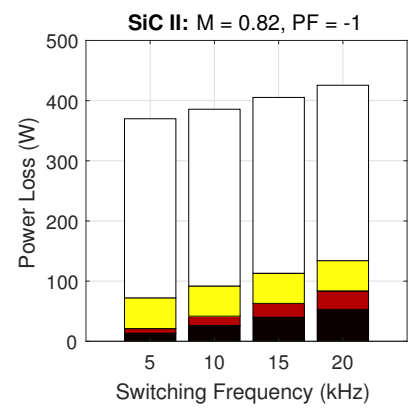

(b)

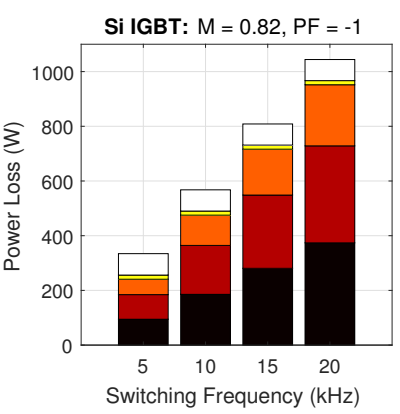

(d)

Fig. 7: AFE losses per switch, $P=1 \mathrm{MW}$. Note the adapted vertical loss scales.

compared to the full-Si module. The distribution of losses between conduction and switching is unfavorable for the whole output power range. A Hybrid module with a lower current rating would be preferred.

The losses in Fig. 8b and their distribution show that SiC II is not suitable for the fully rated HB stage.

\section{4Q Cell - Total Power Losses}

As both stages have different requirements on the switching frequency, we can use the operation at different switching frequencies in the two stages as a degree of freedom for optimization.

The above results are therefor scaled by the number of switches per stage (six and four) and combined in twodimensional plots as Figs. 9 and 10. AFE stage losses are arranged along the abscissa, the inverter HB stage losses along the ordinate. The cell losses are the sum of the two stages. Lines connect the losses of the combined operating points and span a grid for interpolation. The plot assumes that the junction temperature can be kept below maximum up to $20 \mathrm{kHz}$ in any device.

Fig. 9 clearly shows that the full-SiC cells with $\mathrm{SiC}$ II modules are within our loss budget at any frequency and with SiC I modules even at its half. Total losses in a Si IGBT cell are 3 to 6 times higher than in a SiC I cell but lower than in a $\mathrm{SiC}$ II cell if only the lowest plotted frequencies are required.

Possible switching frequency combinations for the Si IGBT cell and Hybrid switch cell are limited by the dotted $4 \%$ line. Disregarding the cooling effort, the highest inverter HB

Fig. 8: Inverter losses per switch, $P=1 \mathrm{MW}$. Note the adapted vertical loss scales.

stage switching frequency that is affordable when the AFE is operated at $1.2 \mathrm{kHz}$ is approximately $10 \mathrm{kHz}$ for the $\mathrm{Si}$ IGBT solution and $13 \mathrm{kHz}$ for the Hybrid switch solution. Taking thermal restrictions into account and driving both stages below $5 \mathrm{kHz}$, the Hybrid module reduces the losses by ca. $25 \%$ compared to Si IGBT. This switching frequency could be enough to convey tests related to the fundamental grid frequency for state-of-the-art sub-megawatt inverters.

Also, different type of modules could be used in the two stages, to optimize the semiconductor costs and performance within the loss budget. Fig. 10 shows a combination of $\mathrm{Si}$ IGBT modules in the AFE stage and SiC I modules in the output stage. The latter reduces the semiconductor losses in the output stage by 5 to 6 times at $1 \mathrm{MVA}$, compared to a full-Si IGBT solution. Moreover, both $20 \mathrm{kHz}$ in the output stage and up to $10 \mathrm{kHz}$ in the AFE stage are within our loss budget. Finally, Fig. 11 shows the 4Q cell efficiencies for a reduced set of switching frequencies in the AFE.

\section{CONCLUSION}

This paper demonstrates effects of using $1.7 \mathrm{kV} \mathrm{SiC} \mathrm{MOS-}$ FET switches on the performances of the high power medium voltage grid emulator, based on the CHB output stage. Compared to Si devices, higher switching frequencies allow significantly better output performances, which are of high importance for voltage quality for analyzed application. While full$\mathrm{SiC}$ solution would improve system efficiency even further, this is judged unnecessary for the AFE stage, where $10 \mathrm{kHz}$ Si operated modules provide sufficiently good performances. 


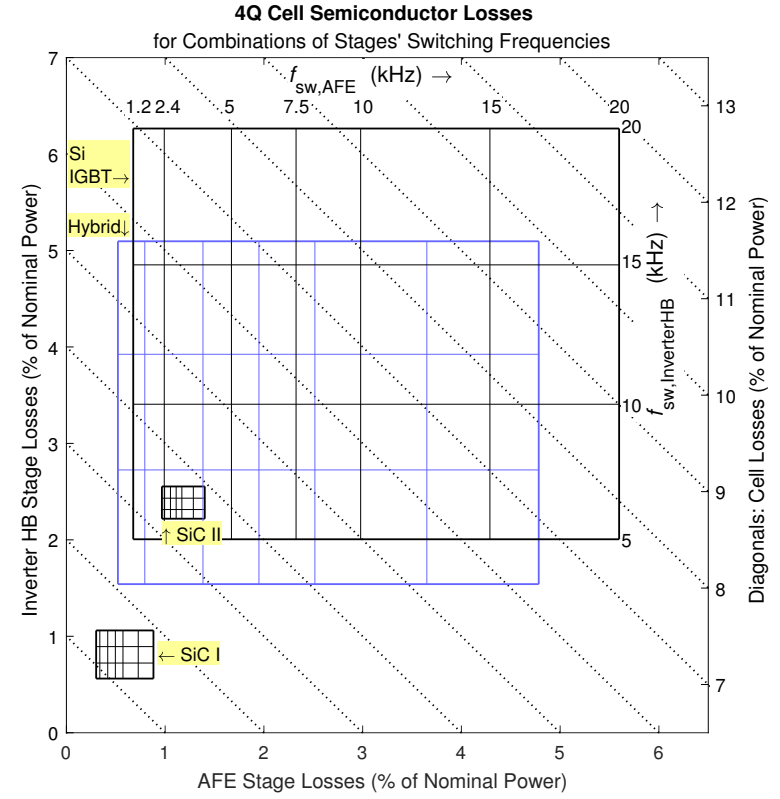

Fig. 9: 4Q cell losses for different switching frequencies in the two stages with same modules in both stages

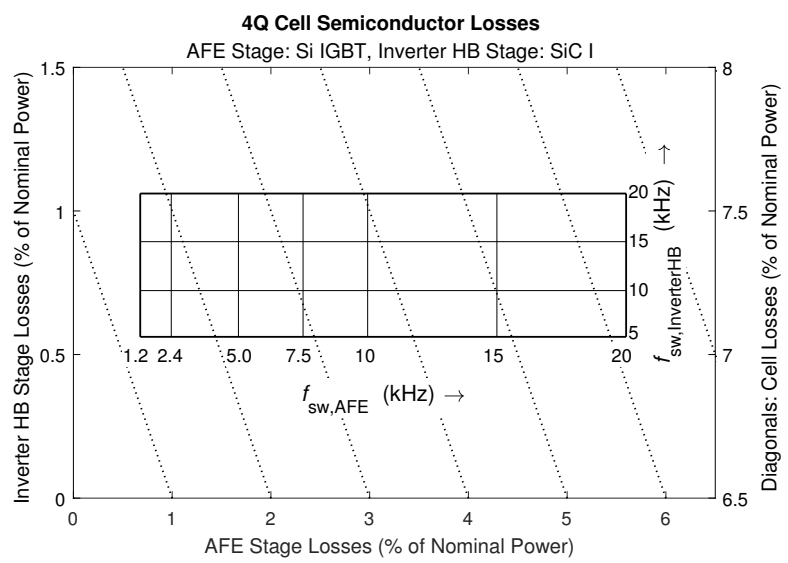

Fig. 10: 4Q cell losses for Si IGBT AFE and SiC I HB at different switching frequencies

\section{REFERENCES}

[1] Y. Yang, F. Blaabjerg, and Z. Zou, "Benchmarking of voltage sag generators," in IECON 2012 - 38th Annual Conference on IEEE Industrial Electronics Society, Oct 2012, pp. 943-948.

[2] A. Hoke, S. Chakraborty, and T. Basso, "A power hardware-in-the-loop framework for advanced grid-interactive inverter testing," in 2015 IEEE Power Energy Society Innovative Smart Grid Technologies Conference (ISGT), Feb 2015, pp. 1-5.

[3] Z. Hong, Z. Xing, L. Fei, L. Fang, and J. Jiehong, "Research of highpower grid simulator system," in 2015 IEEE 2nd International Future Energy Electronics Conference (IFEEC), Nov 2015, pp. 1-3.

[4] G. Si and R. Kennel, "Switch mode converter based high performance power-hardware-in-the-loop grid emulator," in 2016 IEEE 2nd Annual Southern Power Electronics Conference (SPEC), Dec 2016, pp. 1-6.

[5] P. Koralewicz, V. Gevorgian, R. Wallen, W. van der Merwe, and P. Jörg, "Advanced grid simulator for multi-megawatt power converter testing and certification," in 2016 IEEE Energy Conversion Congress and Exposition (ECCE), Sept 2016, pp. 1-8.

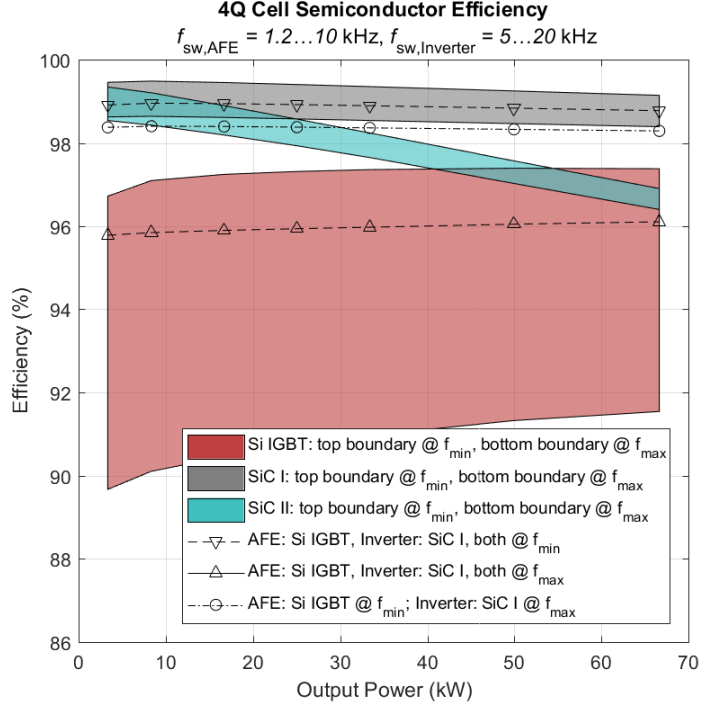

Fig. 11: 4Q cell semiconductor efficiency for switching frequency ranges

[6] A. Schmitt, M. Gommeringer, J. Kolb, and M. Braun, "A high current, high frequency modular multiphase multilevel converter for power hardware-in-the-loop emulation," in PCIM Europe 2014; International Exhibition and Conference for Power Electronics, Intelligent Motion, Renewable Energy and Energy Management, May 2014, pp. 1-8.

[7] J. Kolb, F. Kammerer, A. Schmitt, M. Gommeringer, and M. Braun, "The modular multilevel converter as universal high-precision $3 \mathrm{ac}$ voltage source for power hardware-in-the-loop systems," in PCIM Europe 2014; International Exhibition and Conference for Power Electronics, Intelligent Motion, Renewable Energy and Energy Management, May 2014, pp. 1-8.

[8] Y. Li, Y. Wang, R. Wang, J. Wu, H. Zhang, Y. Feng, S. Li, W. Yao, and B. Q. Li, "Distributed generation grid-connected converter testing device based on cascaded h-bridge topology," IEEE Transactions on Industrial Electronics, vol. 63, no. 4, pp. 2143-2154, April 2016.

[9] E. Ledezma, K. Wang, T. Keister, R. Edwards, R. Pipho, B. Palle, D. Kulkarni, T. E. Salem, J. C. Fox, and L. Parsa, "Development of a modular configurable multi-megawatt power amplifier," in IECON 2013 - 39th Annual Conference of the IEEE Industrial Electronics Society, Nov 2013, pp. 631-636.

[10] Voltage characteristics of electricity supplied by public distribution networks, EN Std. 50 160, 2010.

[11] D. G. Holmes and T. A. Lipo, "Carrier-based pwm of multilevel inverters," in Pulse Width Modulation for Power Converters: Principles and Practice. Wiley-IEEE Press, 2003, ch. 11, pp. 453-530.

[12] J. R. Rodriguez, J. Pontt, M. Perez, P. Lezana, and P. W. Hammond, "High power synchronous machine fed by a cascaded regenerative inverter," in 2008 IEEE Industry Applications Society Annual Meeting, Oct 2008, pp. 1-7.

[13] J. Yao, F. Liu, J. Gong, and X. Zha, "Power recovery and cost reduction oriented optimization of regenerative cells embedded in cascaded multilevel converter," in 2015 IEEE Energy Conversion Congress and Exposition (ECCE), Sept 2015, pp. 5117-5123.

[14] CAS300M17BM2 Datasheet, Rev. A. Wolfspeed. A Cree company, 2014. [Online]. Available: http://www.wolfspeed.com/

[15] APTMC170AM30CT1AG Datasheet, Rev. 1. Microsemi, Dec 2016. [Online]. Available: https://www.microsemi.com/

[16] SKM150GB17E4 Datasheet, Rev. 3. SEMIKRON, April 2015 [Online]. Available: https://www.semikron.com/

[17] 2MSI400VAE-170-53 Datasheet. Fuji Electric, Oct 2017. [Online]. Available: http://www.fujielectric.com/

[18] J. Rabkowski and T. Płatek, "Comparison of the power losses in 1700v si igbt and sic mosfet modules including reverse conduction," in 2015 17th European Conference on Power Electronics and Applications (EPE'15 ECCE-Europe), Sept 2015, pp. 1-10. 